Article 180

Received: September 2, 2020

Accepted: November 24, 2020

\title{
AN OPTIMAL STORAGE ORGANIZATION FOR BLOCKCHAIN-BASED PUBLIC HEALTHCARE SYSTEM
}

\author{
Jovan Karamačoski, Liljana Gavrilovska \\ Faculty of Electrical Engineering and Information Technologies, \\ "Ss. Cyril and Methodius" University in Skopje, North Macedonia \\ jovankaramac@yahoo.com
}

\begin{abstract}
A b s t r a c t: The Blockchain technology nowadays is one of the main trends in IT industry. It has robust structure and creates trustless environment, with extensive data record liveness and accessibility due to its decentralized structure. The applications build on a Blockchain platform have potential to be user-centric with high level of synchronization between the participants. Implementation in a healthcare system can enable development of a usercentric solution for access right management. This will incentivize the patients to participate in the system, but also motivate companies (e.g. pharmaceutical and insurance companies) to shift the business strategies. This paper presents a novel approach for Blockchain-based Healthcare System (BloHeS) that introduces novel record and database organization and significantly decreases database load compared to the classic Blockchain approach. Initial findings and simulation results confirms the storage size reduction, by keeping the robustness of the system.
\end{abstract}

Key words: Blockchain; Healthcare system; network organization; storage size

\section{ОПТИМАЛНА ОРГАНИЗАЦИЈА НА СКЛАДИРАњЕ ПОДАТОЦИ ОД ЈАВНИОТ ЗДРАВСТВЕН СИСТЕМ ВРЗ БАЗА НА ВLОСКСНАIN}

А п с т р а к т: Технологијата Blockchain во денешно време е еден од главните трендови во ИТ индустријата. Има робусна структура и креира околина без доверба, со зголемена трајност и достапност на податочните записи поради својата децентрализирана структура. Апликациите изградени на платформите Blockchain имаат потенцијал да бидат кориснички ориентирани со високо ниво на синхронизација меѓу учесниците. Имплементирањето во здравственот систем би овозможило развој на кориснички ориентирани решенија за управување со правото на пристап. Тоа ќе ги поттикне пациентите да се вклучат во системот, но исто така ќе ти мотивира компаниите (пр. фармацевтските и осигурителните компании) да ги променат бизнис стратегиите. Овој труд прикажува еден нов пристап на здравствените системи базирани на Blockchain (BloHeS) кој вклучува нова организација на записите и базите на податоци и значително го намалува товарот врз базата на податоци споредено со класичниот Blockchain пристап. Иницијалните наоди и симулациски резултати го потврдуваат намалувањето на складишниот обем, зачувувајќ ја робусноста на системот.

Клучни зборови: Blockchain; здравствен систем; мрежна организација; складишниот обем

\section{INTRODUCTION}

The Public Healthcare systems worldwide aim to implement the latest IT technologies to enhance their efficiency. There is trend in digitalization of medical records but also increased awareness for importance of privacy protection of personal information. Current generations of digital healthcare systems are centralized either in the hospital centers or on a cloud storage systems, and generally they are not connected in-between. In both situations the private health-related information are controlled by the hospitals or the cloud storage providers, which opens the possibilities for security breaches and data leakage. A patient-centric solution can overcome these problems. 
The Blockchain technology is a good candidate to provide reliable mechanism for data protection, data management and credential management. This technology provides mechanism for decentralization of data and processes supporting durability, immutability, verifiability and nonrepudiation of records.

In this paper applied Blockchain technology allows the patients to have full control over their personal data, to protect the personal data from unauthorized access and to incentivize the patients to participate in processes for healthcare enhancement. The paper introduces a novel approach for data organization in a Blockchain-based healthcare system towards building a patient-centric solution. That decreases the storage size for the overall Blockchain database. The most significant improvement is on the patient side, where every patient become responsible for management of its own data.

\section{RELATED WORK}

The recent work in the area of Blockchain for healthcare systems is focused on developing platforms compliant to the Ethereum system [1]. Generally, the openness of this system and the big and supportive community is considered as advantage for this approach. The implementation of the healthcare system on top of another Blockchain solution can have drawbacks and limitations. Contrary to this, the private Blockchain solutions are more intuitive due to the sensitive nature of data that circulates in the healthcare systems. However, the closeness of the infrastructure and data management brings distrust in the private Blockchain solutions.

The authors in [2] present a mature approach to Blockchain implementation in a healthcare system. They take into account the need for welldefined structure for medical records and keeps the privacy on the highest level by following the ONC (Office of the National Coordinator) requirements. They introduce the so-called FHIRChain (Fast Healthcare Interoperability Resources Chain) that can be attached on top of any Blockchain technology. This paper stresses the importance of having well-structured and understandable records in order to build an effective system.

MedRec [3] is one of the pioneering work in the Blockchain-based medical record management. The MedRec solution is a smart contract based solution on top of Ethereum Blockchain [1] for complete patient-centric access management. It manage the data storing by segmenting the system in off-
Blockchain data storage and on-Blockchain pointer to data storage. The solution does not provide any privacy and security measures on the local storage component and it has to be provided by the users.

The authors in [4] propose the healthcare data gateway solution that implement private Blockchain to hold the patient data. It has completely developed procedures for mobile application and data access management.

Another Blockchain-based solution implements a self-sovereign identity [5]. Practically the participants in the healthcare system will create digital wallet, paired with an identity-holding Blockchain solution to control the credentials. Basically the proposed system is an access management system for data access rights in other Electronic Health Record (EHR) systems.

Patientory [6] is a solution for EHR on top of Ethereum Blockchain. The solution provides tokenbased access control mechanisms in a private Ethereum Blockchain implementing the FHIR standard for healthcare record structuring. The platform has financial incentive to stimulate the users to participate in the system and collect tokens, later on used for purchasing storage or smart contract invocation.

Medical chain [7] is another solution that offers privacy and security to the patients' healthcare records, but on a private Blockchain platform, called hyperledger fabric. Similar to the patientory solution, Medical chain offers implementation of tokenized economy to incentivize the users of the platform.

The listed Blockchain-based healthcare systems solutions are the most prominent ones. Besides, many other solutions can be found in the literature, generally presenting developed applications build on top of the current mainstream Blockchain platforms (like Bitcoin and Ethereum).

\section{NOVEL APPROACH FOR BUILDING PUBLIC HEALTHCARE SYSTEMS}

This paper describes the network and the storage organization of a new BloHeS (Blockchainbased Healthcare System) system, which is built in addition to the previously proposed architecture [8] and the scalability improvement mechanisms [9]. The proposed architecture in [8] defines five layers structure for the next generation Blockchain-based healthcare systems. The segmentation in layers is done to create independence between the techniques and technologies used in every layer. This will make 
the system to be easily upgradable in every segment. The architecture also splits the user-layer horizontally in several segments in order to emphasize the differences in the procedures required for the different participants. The mechanisms for scalability improvement introduced in [9] are generally designed toward segmentation of the nodes depending on their role in the network, network latency between the nodes or their physical location in the network. The general distinction of the proposed BloHeS system to the available solutions on the market, is the management of the medical records supported by the Blockchain technology's advancements. It is focused on developing a Blockchain-based system for massive usage and improves the scalability aspects present in the current Blockchain implementations. It enables the patient-centric system solution that brings the management of private data in the patients' hands.

\section{A) Types of agents}

The BloHeS system defines four types of agents, as major architectural building blocks:

- Healthcare practitioner agent. It is fully functional node that implements optimal database and is capable of conducting verification processes of the underlying Blockchain protocol, patient wallet generation procedure, input data, store patients' data and managing patients' databases.

- Governmental agent, which is fully functional node with complete database of every patient in the network. It is capable to monitor the Block- chain protocol implementation in the whole network.

- Patient's agent. This agent is lightweight node, with optional capabilities to conduct verification processes, depending on the financial incentives introduced by the Government. The patient's agent main role is to manage the access rights for the personal data. Furthermore, this agent is able to manage the home gateway devices or IoT devices, paired under the patient's consent.

- Public agent, which is a lightweight node available for pharmaceutical companies, insurance companies or Artificial Intelligence enabled nodes. This agent has only read permissions to the publically available patients' data.

\section{B) Network architecture}

The proposed BloHeS architecture focuses on scalability (data storage, verification throughput, latency and address space scalability) and the power efficiency of Blockchain system, which are wellknown weaknesses for the current public Blockchain implementations (like Bitcoin and Ethereum). The authors in [9] introduces three different approaches for architecture design to overcome some of the most common drawbacks of current Blockchain technologies. Each of these approaches focuses on some aspects, but none of the proposed solutions tackles all aspects at once. For further improvement on the proposed designs in [9], this paper introduces advanced combination of the three proposed architecture designs, organized into a single multilevel network structure, as depicted in Figure 1.

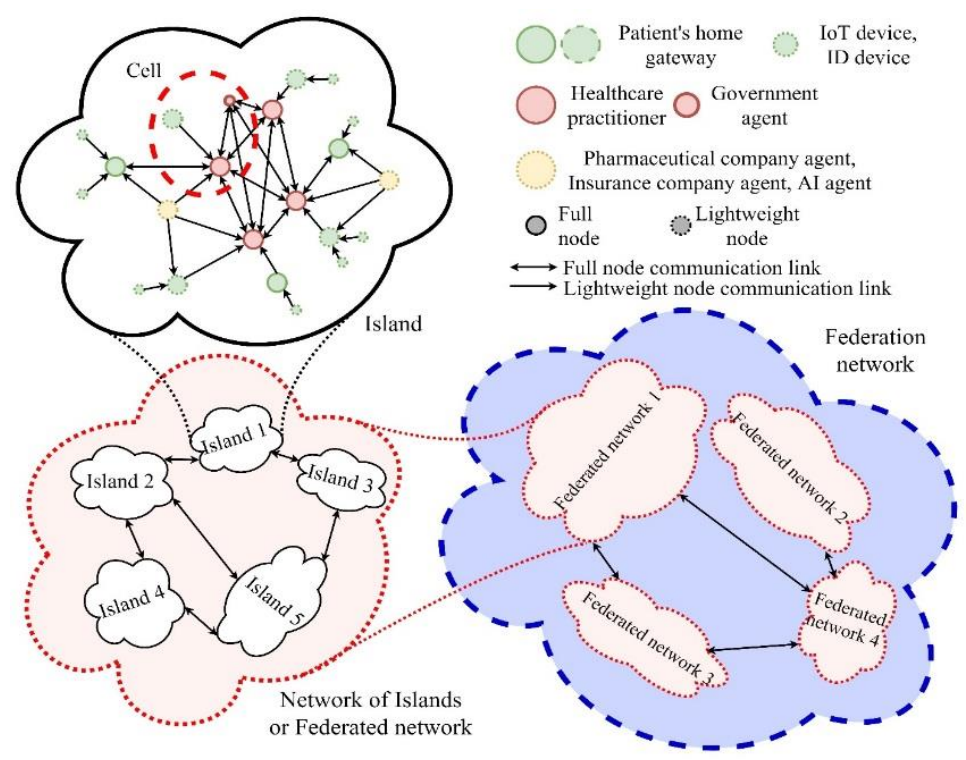

Fig. 1. BloHeS network organization 
The first level that is also the smallest organizational unit of the network, is called Cell. It is created by patient's agent and healthcare practitioner agent. For enhanced functionality and robustness of the system, mandatory trusted party of the Cell will be the Governmental agent. Optionally, the patient can add more agents to the Cell, like a trusted home gateway (as anchor point for storing the health records) and IoT devices (as comfort extender or data tracker). The carrier of the Cell unit is the patient's agent, by continuously supporting and managing the patient's Personal Blockchain Stream (PBS), introduced in [9]. The PBS represents the personal Blockchain-based healthcare record database.

The Islands present the second level. They are temporal logical formation of healthcare practitioner agents, networked to each other on a predefined latency timing to optimize the consensus algorithm for extended scalability. Using the self-organization algorithms, the healthcare practitioner agents can determine the most optimal network of agents to fulfil the pre-required latency for data propagation. In the BloHeS we are proposing formation of Islands only by healthcare practitioner agents. Optionally a patient agent can participate in existing island in the process of verification, depending on the financial incentive introduced by the Government.

The third level is the Network of islands that represents a Federated network. The Network of islands or the Federated network is the highest autonomous organization unit, resembling the country borders and will be logical organization unit guided by the current law enforcing regulations. The implementation of smart contracts allows to reflect the Governmental regulation in the BloHeS system.

The highest level is the Federation network. A Federation network is constituted from Federated networks that can establish tighter relations and mutual collaboration with other Federated networks depending on the inter-country agreements. The establishment of the Federation network, enhances the flexibility for patients to move across the countries and get hospitality according their needs.

\section{C) Database organization}

The first step in the process of developing optimal database organization is to adopt a standard structure of data records. Currently there are several standards for electronic healthcare record structures with main goal to reach high level of interoperability between the systems. BloHeS is following this approach, because it is the main factor for faster and better acceptance by the population.
Two general types of databases compose the BloHeS system in order to better reflect the logical segmentation of the system between the patients, the healthcare practitioners and the Government. The main databases are the Patient database and the Common database. Further, the Common database is divided in Island database and Federated network database. The following subsections elaborate in more details the electronic healthcare records and the defined databases.

\section{Electronic healthcare record structure}

To provide the high level of interoperability, the system must employ consistent record formats for healthcare records on Personal Blockchain Stream, achieved by implementation of one of the existing healthcare record standards. The authors in [10] present comparison between several EHR (Electronic Healthcare Record) standards and protocols. The main distinction regards the content structure and the access services. The major design's interest focuses on international standards that define the content structure, while the access service standards are covered by the Blockchain functionalities. The authors in [10] points on three international standards: EHRcom (Electronic Healthcare Record Communication), HL7 CDA (Health Level 7 Clinical Document Architecture) and DICOM SR (Digital Imaging and Communications in Medicine Structured Reporting), and one nationwide standards, MML (Medical Markup Language), created for the Japanese healthcare system.

For a good content structuring standard it is important to define huge amount of templates and archetypes, moreover it is important to be futureproof by implementing content descriptions that have machine-understandable semantic. An effective semantic statements in a healthcare records can be generated by use of a vocabulary of terms and conditions like the ones defined in the following standards: SNOMED CT (Systematized Nomenclature of Medicine - Clinical Terms) and GALEN (Generalized Architecture for Languages, Encyclopedias and Nomenclature). This enables the semantic interoperability between the standards. The semantic interoperability is very important property that boosts the efficient machine learning algorithms, capable to predict personal health conditions, general population health condition and epidemics. This property is a precondition for successful implementation of AI (Artificial Intelligence) module in the BloHeS architecture. 


\section{4Patients and Common databases}

The Patient database is the record keeping structure found in the healthcare practitioner agents, containing pluggable sub-database data structure, build from Personal Blockchain Streams (Figure 2). The Personal Blockchain Stream (PBS) is the smallest database element which represents personal Blockchain database structure of patient's electronic healthcare records. The recorded PBSs in the Patient database are only from the patients who have chosen the particular healthcare practitioner as a family healthcare practitioner or from the patients who have visited the healthcare practitioner. Every patient manages its own PBS and gives access rights or shares its own complete PBS with the personal healthcare practitioner. The Governmental agent keep the complete list of PBSs from every citizen. Depending on the patient's preferences, the PBS in the Patient database can be unencrypted (by giving permanent read credentials) or encrypted (by giving temporal/per visit, read credentials). The presence of separate database structure to store the patients' PBS give opportunity to build patient-centric solution and give the patients an ability to manage their personal data, move between the healthcare practitioners, share with companies or other institutions. This is the basic reason for building dedicated database for patients' PBS in the healthcare practitioner agent.

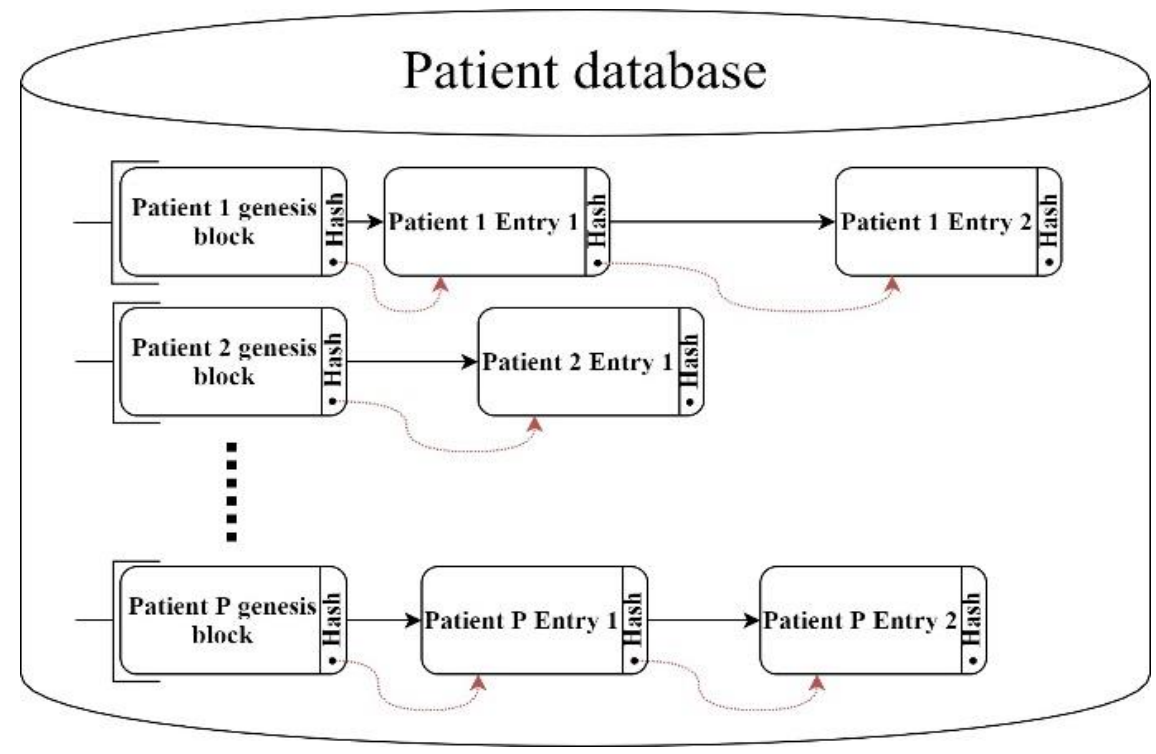

Fig. 2. Patient database

The Island database has temporal nature, and has no Blockchain structure (Figure 3). The Island database is structured from instances of every entry created in the Island and verifications for the entries from the other agents in the network. Mainly the reason for existence of a temporal database is to create set of agents who work on a consensus mechanism to keep the data correct and declog the main network from redundant messages.

The Federated network database has permanent nature and will keep the finite data, synchronized among every healthcare practitioner agent in the Federated network (Figure 3). The Federated network database has Blockchain structure with block records created from a list of record addresses made in every Island database in the network. For Inter-Federated network communication and for distinguishing the Federated network domains by countries, the system uses country identification tag. The tag enables better traffic routing and managing the patients' data.

The procedure for record insertion starts from the healthcare practitioners, where the healthcare practitioner generates a record for the patient during every visit. During the patient's visit, the healthcare practitioner requests access to the patient's personal Blockchain stream (the access approval is either granted without time limitation or it is set up per visit). The patient record contains hash value from the previous record, time stamp of visit, diagnoses, examination results, prescribed therapy and hash value from the current record. Practically the hash value of the record is the address to the patient records. The generated record is verified by the 
healthcare practitioner agent and send to the healthcare practitioner agents that participate in the same Island. Generally the other participant in the Island are only verifying the correctness of the record structure and hashing done by the main healthcare practitioner agent, since the data inserted in the record is encrypted and not visible for verification and validation. Optionally the personal agent of the patient can check the unencrypted form of the record for hashing correctness. If the record is correct it is verified by the Island participants and set in the Island database for further procedure of building common database and common truth.
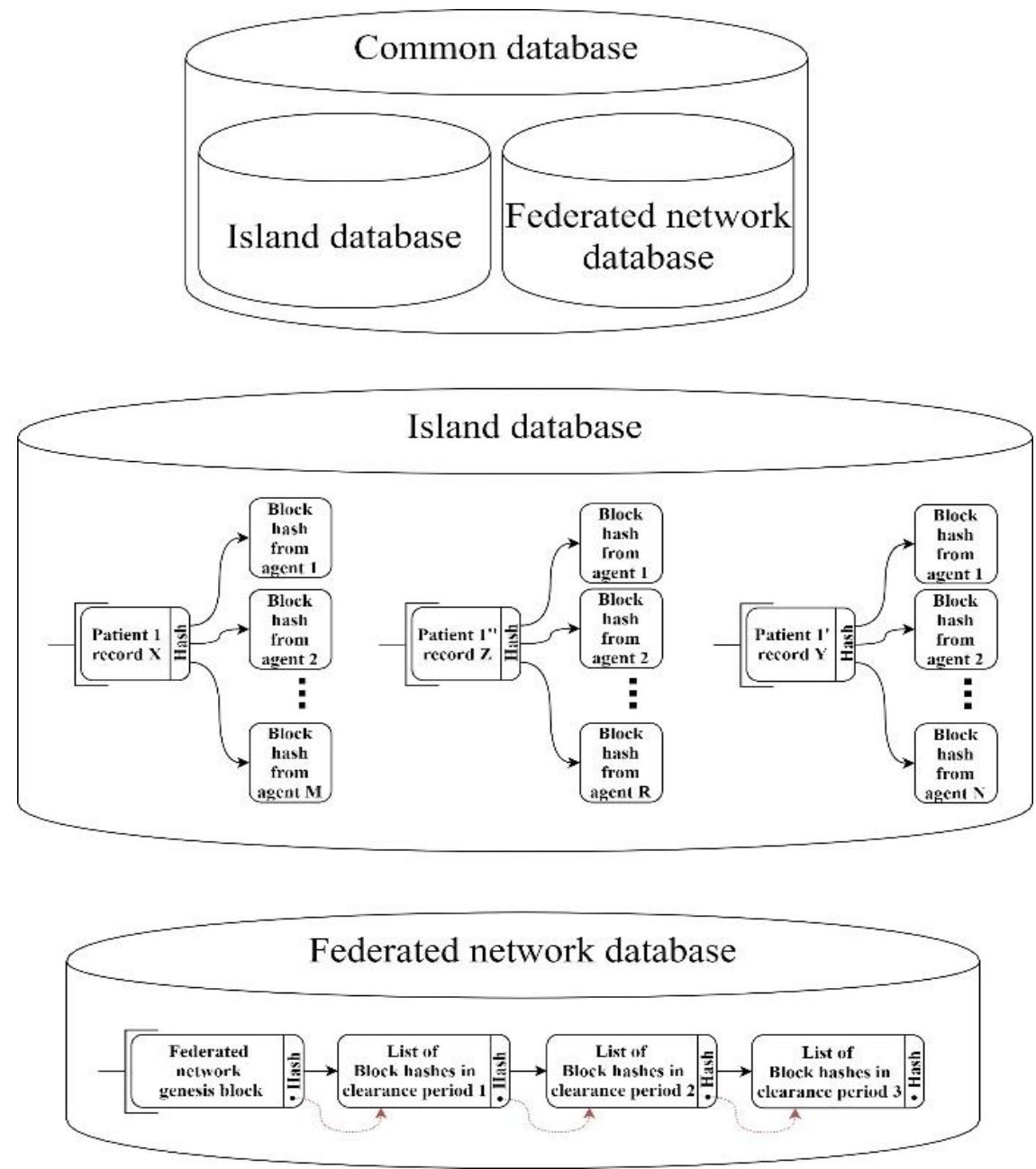

Fig. 3. Common database, Island database and Federated network database

The participants in the Island, are voting for correctness of data in the Island database. After finalization of the voting process the address of the record is sent to the Governmental agent for final arrangement of the block record in the Federated network database. The Governmental agent creates the ordered list of record addresses, finalize the block records and announces it to every healthcare practitioner agent (e.q. every healthcare practitioner agent writes the block in the Federated network database). Selected Island participants are regularly checking the correctness of the records send by the Governmental agent. Any alerting situation halts the
Governmental agent and initializes the distributed block records arrangement for Federated network database.

\section{STORAGE SCALABILITY ANALYSIS AND SIMULATION RESULTS}

The initial analysis of the BloHeS architecture promises improvement over the healthcare system architecture based on classical Blockchain, such as Ethereum. This section presents mathematical analysis and simulation results for storage capacity consumption over time, comparing both solutions. 


\section{A) Classical Blockchain storage organization}

The standard approach of managing the common distributed database in a classical Blockchain solution (like Bitcoin and Ethereum) is to handle the complete transaction database in every participating node. This means that the complete common database is handled by all participants in the network. In a healthcare system scenario this means that every generated record by every healthcare practitioner in the system, must be replicated in every node in the network. Obviously, this approach is infeasible for networks with huge number of participants. The total system storage (cumulative storage of all participating nodes) per day in the network will be calculated as in (1):

$$
S_{t}^{c}=F \times v \times H_{p} \times\left(N+H_{p}+G\right) .
$$

where $S_{t}^{c}$ is total storage per day in a classical Blockchain system, $F$ is average record size, $v$ is average number of visits in the practitioners' office per day, $H_{p}$ is number of healthcare practitioners in the Federated network, $N$ is number of patients in the Federated network, $G$ is number of Governmental agents.

Taking into account the 3 basic agents: patient, healthcare practitioner and Governmental agent, we can estimate the total daily storage in every agent separately, which will be calculated with (2):

$$
S_{p}^{c}=S_{h p}^{c}=S_{g}^{c}=F \times v \times H_{p},
$$

where $S_{p}^{c \mathrm{c}}$ is patient storage per day in a classical Blockchain system, $S_{h p}^{c}$ is healthcare practitioner storage per day in a classical Blockchain system, $S_{g}^{c}$ is Governmental storage per day in a classical Blockchain system. The other variables are defined in (1).

\section{B) Optimal storage organization for BloHeS architecture}

Our proposal to decrease the storage capacity burden is to decrease the number of replicas in the whole system, but still maintain the robustness of the Blockchain technology regarding the data replication and liveness. The organization of the databases in the BloHeS architecture offers the ability to manage only personal Blockchains. Basically the end users will only manage their personal database which will increase in size, depending only on their personal health conditions and the number of visits by the patient. For this reason the main storage burden will be only on the healthcare practitioner agents and Governmental agent.
According the BloHeS architecture guidelines, the approach for storing data is to keep minimum 3 replicas per patient in the whole system (in the patient agent, in the healthcare practitioner agent and in the Governmental agent). The replication factor of 3 is commonly accepted as bare minimum to offer sufficient redundancy in a traditional distributed storage systems. With this approach the total storage in the whole system per day will be calculated with (3):

$$
\begin{aligned}
S_{t}^{B}= & F \times v \times H_{p} \times r+C D S \times F \times v \times H_{p} \times \\
& \times\left(H_{p}+G\right),
\end{aligned}
$$

where $S_{t}^{B}$ is total storage per day in a BloHeS system, $F$ is average record size, $v$ is average number of visits in the practitioners' office per day, $H_{p}$ is number of healthcare practitioners in the Federated network, $r$ is number of replications per patient, $C D S$ (Common Database Storage) is storage factor showing the record size in the Common database compared to the real record size in the PBS, $G$ is number of Governmental agents.

The storage consumption per day for the separate agents will be calculated as presented with (4) for the patient agent and (5) for the healthcare practitioner agent:

$$
\begin{gathered}
S_{p}^{B}=F \times v^{\prime} / 365 \\
S_{h p}^{B}=F \times v+C D S \times F \times v \times H_{p}
\end{gathered}
$$

where $S_{p}^{B}$ is patient storage per day in a BloHeS system, $S_{h p}^{B}$ is healthcare practitioner storage per day in a BloHeS system, $v$ ' is average patient visits per year, the other variables are defined in (3).

Obviously the largest load will be on the Governmental agent as shown with (6):

$$
S_{g}^{B}=F \times v \times H_{p}+C D S \times F \times v \times H_{p},
$$

where $S_{g}^{B}$ is Governmental agent storage per day in a BloHeS system and the other variables are defined previously in (3).

The Common Database Storage (CDS) variable has minimal impact on the total storage because the content in the Common database is practically referral links to the actual locations of the records. Taking in to account a referral link of 128 bytes or 256 bytes, and comparing it to actual record in the database, for example, textual record of around $1 \mathrm{~KB}$ or media record of several $\mathrm{MB}$, we can assume that the Common database will occupy only $1 \%$ of the actual record size. Under this assumption the CDS factor is set to 0.01 . 


\section{C) Simulation results}

This subsection presents the comparison between the BloHeS architecture and the classical Blockchain approach based on the system behavior highlighted with (1) - (6). The MATLAB simulation considers a countrywide system (actually a Federated network) with $10^{6}$ and $10^{9}$ patients.

The working parameters are consulted by literature. The authors in [11], [12] and [13] analyze parameters' range regarding the panel size for the healthcare practitioners and the patients' healthcare habits. The panel size presents the number of individual patients under care of one healthcare practitioner and varies between the countries and ages of the patients. Table 1 shows the parameters' range and simulation values for panel size, average number of visits per patient per year, number of provider visits per day and number of provider's working days per year.

Table 1

Simulation parameters

\begin{tabular}{lcc}
\hline \hline & $\begin{array}{c}\text { Parameters } \\
\text { range }\end{array}$ & $\begin{array}{c}\text { Simulation } \\
\text { values }\end{array}$ \\
\hline $\begin{array}{lcc}\text { Panel size of a healthcare practi- } \\
\text { tioner }\end{array}$ & $1500-2500$ & 1806 \\
$\begin{array}{l}\text { Average number of visits per } \\
\text { patient per year }\end{array}$ & 3 & 3.19 \\
$\begin{array}{l}\text { Number of provider visits per day } \\
\begin{array}{l}\text { Number of provider's working } \\
\text { days per year }\end{array}\end{array}$ & $10-30$ & 24 \\
\hline \hline
\end{tabular}

The particular simulation values are according [13]. To get the sense of the storage impact for a countrywide solution, the population for a Federated network is assumed to be $10^{6}$ and $10^{9}$ inhabitants. The optimal number of healthcare practitioners in a Federated network is calculated according the relations in [14] as a ratio of the number of patients in the Federated network over the panel size.

The Government in the network will participate with at least 1 agent in order to conduct the procedures related with the Governmental role in the network. Some of the processes conducted by the Governmental aim to obtain a guaranteed point of storage (storing the third replica of the records) and act as mediator in processes of dispute. The number of Governmental agents could be increased depending on the implementation scenario, but this will also significantly increase the expenditures for the Government (higher number of Governmental agents will decrease the latency for data access in a big networks). The CDS factor is 0.01 as previously explained. Regarding the record size, in the simulation it is assumed an average record size of $1 \mathrm{~KB}$ which in reality is sufficient to write complete diagnose and other supporting information for the visit.

The following figures present the comparison of the cumulative storage size for extended period of time (10 year period) both for the classical approach and BloHeS approach, for $10^{6}$ and $10^{9}$ patients. The results are presented in a logarithmic scale in order to increase the visibility of the difference between the curves. Figure 4 presents the comparison of the predicted cumulative Blockchain size for the whole healthcare system, including the patients' storage, healthcare practitioners' storage and Governmental storage. The improvements, e.g. the reduction of the storage size is obvious, and shows the potential of the storage savings with BloHeS approach. The figure shows the influence of the population, confirming the infeasibility of the classical Blockchain implementation for a long-term usage, especially for the large number of patients.

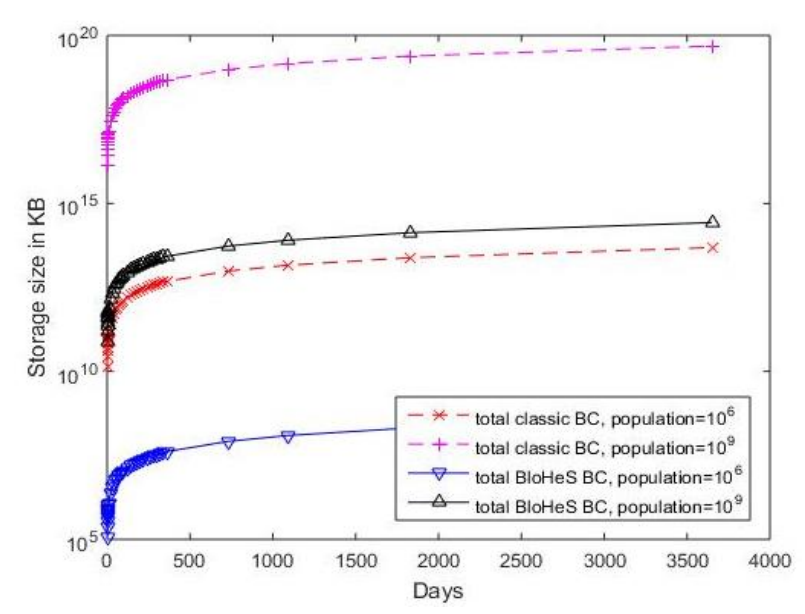

Fig. 4. Cumulative storage size for complete healthcare network

Figure 5 shows the comparison of the cumulative patients' storage for classical approach and BloHeS approach for a period of 10 years. It is obvious that the classical approach put pressure on the patients' storage even if the patient does not visit the healthcare practitioner. The BloHeS approach requires smaller patients' databases due to database personalization. The classical approach affects the patients' database with data records from other users, especially in large networks with big number of patients. 


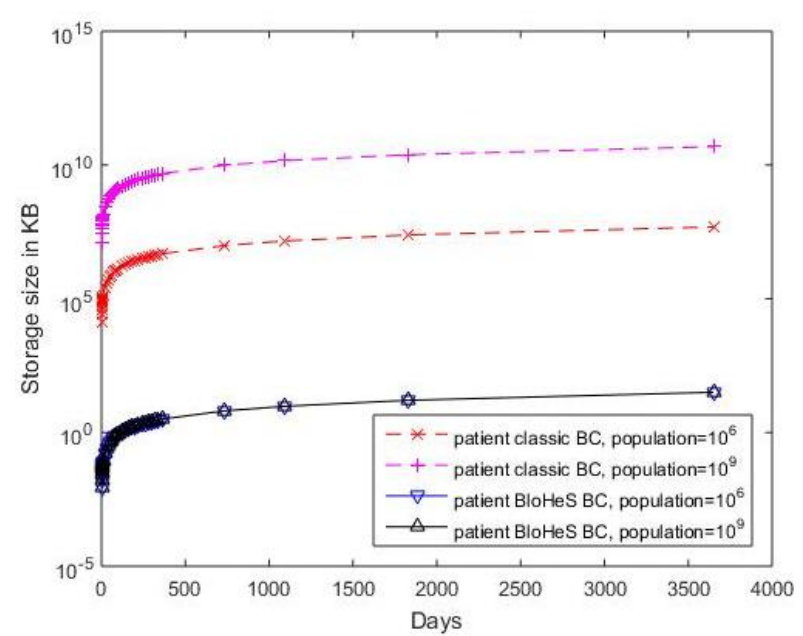

Fig. 5. Cumulative storage size in the patient's storage

Figure 6 shows the cumulative healthcare practitioners' storage for a period of 10 years. Again the figure shows the advantage of the BloHeS approach over the classical one. Still there is an impact over the healthcare practitioners' storage, but it is only from the patients who are selecting the healthcare practitioner for personal caregiver, not from every participant in the network, which is big burden in a large network scenarios. Contrary to the previous results and presented improvements, from Figure 7 it is obvious that there are no improvement over the Governmental agent. This is expected result due to the nature of the system and the need for the Government to keep the patients' records and the whole healthcare system.

Table 2 presents the cumulative storage size for different population and for different time periods (overview after 1 year and 10 years of use). It is obvious that the BloHeS approach significantly reduces the patients' storage size, compared to the classical approach, independently of the network size. The healthcare practitioners' agent has decreased the storage load but is still affected by the population size. From the Table 2 it is obvious that the BloHeS approach insignificantly increases the storage load on the Governmental agent compared to the provided benefits.

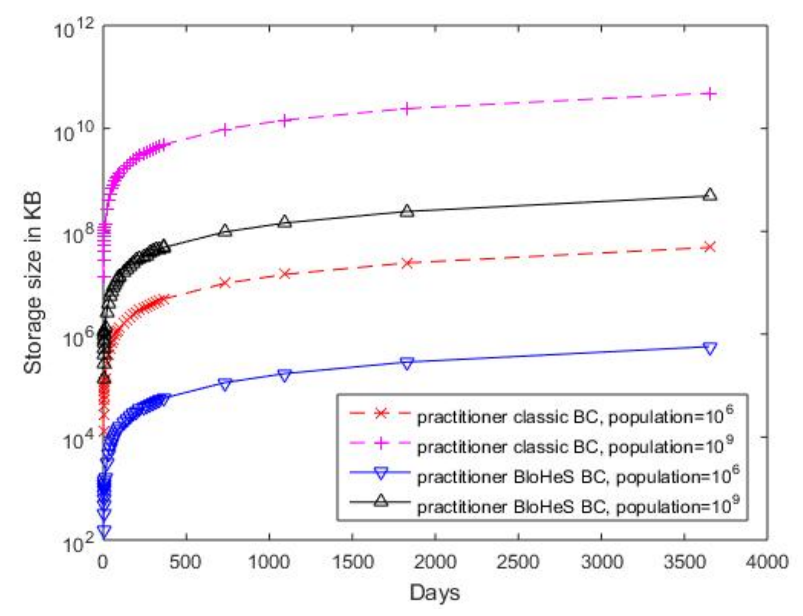

Fig. 6. Cumulative storage size in the healthcare practitioner's storage

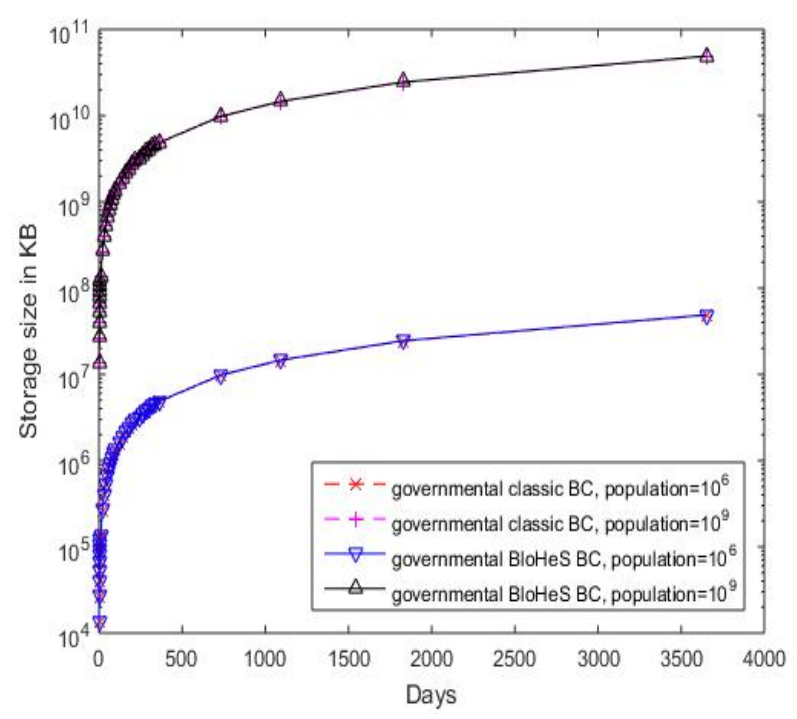

Fig. 7. Cumulative storage size in the Governmental storage

Table 2

Comparison of Blockchain size for 1 and 10 years period for networks of $10^{6}$ and $10^{9}$ patients in the classical and BloHeS approach

\begin{tabular}{|c|c|c|c|c|c|c|c|c|}
\hline \multirow{3}{*}{ Blockchain architecture } & \multicolumn{4}{|c|}{ Population of $10^{6}$} & \multicolumn{4}{|c|}{ Population of $10^{9}$} \\
\hline & \multicolumn{2}{|c|}{1 year period } & \multicolumn{2}{|c|}{10 years period } & \multicolumn{2}{|c|}{1 year period } & \multicolumn{2}{|c|}{10 years period } \\
\hline & Classical & BloHeS & Classical & BloHeS & Classical & BloHeS & Classical & BloHeS \\
\hline Total storage (Kilobytes) & $4.85 \cdot 10^{12}$ & $4.15 \cdot 10^{7}$ & $4.85 \cdot 10^{13}$ & $4.15 \cdot 10^{8}$ & $4.85 \cdot 10^{18}$ & $2.69 \cdot 10^{13}$ & $4.85 \cdot 10^{19}$ & $2.69 \cdot 10^{14}$ \\
\hline Patient storage (Kilobytes) & $4.85 \cdot 10^{6}$ & 3.19 & $4.85 \cdot 10^{7}$ & 31.9 & $4.85 \cdot 10^{9}$ & 3.19 & $4.85 \cdot 10^{10}$ & 31.9 \\
\hline $\begin{array}{l}\text { Healthcare practitioner storage } \\
\text { (Kilobytes) }\end{array}$ & $4.85 \cdot 10^{6}$ & $5.73 \cdot 10^{4}$ & $4.85 \cdot 10^{7}$ & $5.73 \cdot 10^{5}$ & $4.85 \cdot 10^{9}$ & $4.85 \cdot 10^{7}$ & $4.85 \cdot 10^{10}$ & $4.85 \cdot 10^{8}$ \\
\hline Governmental storage (Kilobytes) & $4.85 \cdot 10^{6}$ & $4.90 \cdot 10^{6}$ & $4.85 \cdot 10^{7}$ & $4.90 \cdot 10^{6}$ & $4.85 \cdot 10^{9}$ & $4.90 \cdot 10^{9}$ & $4.85 \cdot 10^{10}$ & $4.90 \cdot 10^{10}$ \\
\hline
\end{tabular}




\section{CONCLUSION}

The Blockchain technology shows good characteristics and potential for implementation in many use-case scenarios. The healthcare system can benefit by providing decentralization of data and processes, patient-centricity of the access right management and automation of the processes through Smart contracts.

This paper presents the novel BloHeS solution for optimized database organization and patientcentric record management for Blockchain-based healthcare systems. The simulation results show significant overall storage reduction in the BloHeS over the classical Blockchain approach. The most significant storage reduction is present in the patient agent, where the BloHeS proposes keeping only the personal data. That is opposite from the classical approach where the patient node keep the patient data from all participants in the network. Less significant storage reduction is present in the healthcare practitioners' agent. No storage reduction is present only in the Governmental agent, since every patient need to provide master copies. Contrary, the Governmental agent slightly increases the storage size. This is negligible compared to the overall benefit achieved in the users' agents.

The reduction of the overall storage in a Blockchain system contributes to increased scalability of the system. Moreover, the patient storage reduction leads to better adoption of this solution by the users. The BloHeS solution can optimize the performances of the system and maximize the benefits for the patients.

\section{REFERENCES}

[1] Buterin, V.: Ethereum white paper: A next-generation smart contract and decentralized application platform, http://blockchainlab.com/pdf/Ethereum_white_paper-a_n ext_generation_smart_contract_and_decentralized_applic ation_platform-vitalik-buterin.pdf, 2014.

[2] Zhang, P., White, J.: FHIRChain: applying blockchain to securely and scalably share clinical data, Computational and Structural Biotechnology Iournal, Vol. 16, pp. $267-$ 278 (2018)

[3] Azaria, A., Ekblaw, A.: Medrec: Using blockchain for medical data access and permission management, Proceedings of the Conference (2nd International Conference on Open and Big Data $(O B D))$, pp. 25-30, 2016.

[4] Yue, X., Wang, H.: Healthcare data gateways: found health care intelligence on blockchain with novel privacy risk control, Journal of Medical Systems, Vol. 40, no. 10, p. 218, (2016).

[5] Gropper, A.: Powering the physician-patient relationship with HIE of one blockchain health IT, Proceedings of the Conference (ONC/NIST use of Blockchain for healthcare and research workshop), 2016.

[6] McFarlane, C., Beer, M.: Patientory: A Healthcare Peerto-Peer EMR Storage Network, Vol.1,

https://www.colleaga.org/sites/default/files/attachments/p atientory_whitepaper.pdf, (2017).

[7] Medicalchain: Medicalchain Whitepaper 2.1, (2018) https: //medicalchain.com/Medicalchain-Whitepaper-EN. pdf,

[8] Karamachoski, J., Gavrilovska, L.: Framework for next generation of digital healthcare systems, Proceedings of the Conference (Future Access Enablers for Ubiquitous and Intelligent Infrastructures, 4th EAI International Conference, FABULOUS), pp. 12-24, 2019.

[9] Karamachoski, J., Gavrilovska, L.: Toward scalable architecture for the next generation Blockchain-based healthcare systems, Proceedings of the Conference (Balkancom), pp. 1-5, 2019.

[10] Eichelberg, M., Aden, T.: A survey and analysis of electronic healthcare record standards, ACM Computing Surveys (Csur), Vol. 37, No. 4, pp. 277-315 (2005)

[11] Altschuler, J., Margolius, D.: Estimating a reasonable patient panel size for primary care physicians with teambased task delegation, The Annals of Family Medicine, Vol. 10, No. 5, pp. 396-400 (2012).

[12] Baron, R. J.: What's keeping us so busy in primary care? A snapshot from one practice, The New England Journal of Medicine, Vol. 362, No. 17, pp. 1632-6 (2010).

[13] Murray, M., Davies, M.: Panel size: how many patients can one doctor manage?, Family Ppractice Management, Vol. 14, No. 4, p. 44 (2007).

[14] Muldoon, L., Dahrouge, S.: How many patients should a family physician have? Factors to consider in answering a deceptively simple question, Healthc Policy, Vol. 7, No. 4, pp. 26-34, (2012). 